\title{
ABANDONADOS POR UNS, OCUPADOS POR OUTROS: \\ EDIFÍCIOS DE APARTAMENTOS NO CENTRO PAULISTANO
}

\section{ABANDONED BY SOME, OCCUPIED BY OTHERS:}

\author{
APARTMENT BUILDINGS IN DOWNTOWN SÃo PAULO \\ Felipe Anitelli A, B, C, D, E, F \\ Universidade de São Paulo, Faculdade de Arquitetura e Urbanismo, São Paulo, São Paulo, Brasil \\ Marcelo Tramontano a, B, C, D, e, F \\ Universidade de São Paulo, Instituto de Arquitetura e Urbanismo, São Carlos, São Paulo, Brasil
}

\begin{abstract}
R E S U M O : O principal objetivo deste artigo é compreender as demandas e as açôes de movimentos populares por moradia no centro de Sáo Paulo e situá-las nas recomendaçôes da legislação vigente, que estabelece a noção de função social da propriedade urbana e indica os mecanismos para coibir a especulação imobiliária. É nesse contexto que esses movimentos ganham vulto e presença no embate político. A ação mais transgressora e, ao mesmo tempo, controversa são as ocupaçóes de edifícios ociosos. São essas questóes que conduzirão as argumentaçốes deste texto, embasado em uma revisão bibliográfica, em reportagens exibidas em jornais e em documentários publicados em websites. Uma das conclusôes mais evidentes é que as reivindicaçôes desses movimentos populares e a maneira como os moradores das ocupaçôes autogerem o espaço coletivo do edifício e compartilham seu cotidiano doméstico conflitam com as políticas públicas habitacionais tradicionalmente adotadas, conflitam, inclusive, com interesses econômicos de promotores imobiliários normalmente beneficiados por essas políticas.
\end{abstract}

P A L A V R A S - C H A V E : habitação social no centro; movimentos sociais por moradia; política pública habitacional; ocupação de edifícios ociosos; centro de São Paulo.

A B S T R A C T : The main objective of this article is to understand the demands and actions of social housing movements in the center of Säo Paulo, and situate them according to the recommendations of current legislation, which has established the concept of the social function of urban property, and indicates the mechanisms with which to restrict real estate speculation. It is within this context that these social movements have increased their importance and presence within political debate. The most transgressive and at the same time, controversial action relates to the occupation of unused buildings. These are the issues which have led to the arguments contained within this paper, based on a literature review, as well as newspaper reports and documentaries published on websites. One of the evident conclusions is that there is a direct conflict between the demands of the social movements and the manner in which those taking part in the occupations self-manage the common spaces of the buildings and share their daily housework and the traditionally adopted public housing policies and the economic interests of the real estate agents, who are generally benefited by these policies.

K E Y W O R D S : social housing in downtown; social movements for housing; public policy for housing; unused building occupation; São Paulo downtown.

DOI: http://dx.doi.org/10.22296/2317-1529.2016v18n1p77

Contribuição de cada autor: A. fundamentação teórico-conceitual e problematização; B. pesquisa de dados e análise estatística; C. elaboração de figuras e tabelas; $\boldsymbol{D}$. fotos; E. elaboração e redação do texto; F. seleção das referências bibliográficas. 
10 relatório encontra-se disponível para consulta desde o dia 10 de dezembro de 2014 (Disponível em: <http://www.cnv.gov.br/>. Acesso em: 23 jul. 2015).
20 ambiente cultural do período também é reconhecido por Ferreira (2005, p. 15): "A ditatura militar desmontou a mobilização da sociedade civil em torno das grandes reformas sociais, inclusive a urbana, substituindo-a por um planejamento urbano centralizador e tecnocrático".

30 Estatuto da Cidade, Lei n.o 10.257, de 2001, talvez seja o principal exemplo aglutinador dessas regulamentações.

4 Por exemplo, Movimento de Moradia no Centro, Movimento de Defesa do Favelado e Associação por Habitação com Dignidade.]

5 Por exemplo, Leva (Disponível em: <https://www. youtube.com/watch? $v=x n 2 u m 8 x h c 40>$. Acesso em: 14 jul. 2015) e Torre de Babel (Disponível em: <https://www.youtube.com/ watch?v=|6nJwa 0mTA $>$. Acesso em: 14 jul. 2015); entre outros.

6 Neste trabalho, adotouse o mesmo nome que os movimentos por moradia costumam usar, ou seja, "ocupações". Decidiu-se não usar, em nenhuma circunstância, o termo "invasão", como normalmente aparece em reportagens jornalísticas que tratam da questão.

\section{INTRODUÇÃO}

O golpe de Estado de 1964, que pôs as Forças Armadas no poder, e as subsequentes gestóes públicas autoritárias inibiram ou proibiram, com sistemática violência, mobilizaçôes populares que reivindicassem reformas sociais e políticas. O relatório final da Comissão Nacional da Verdade investigou, reconheceu e publicou diversos crimes sabidamente ocorridos no período ${ }^{1}$. A postura autoritária dos governos certamente prejudicou debates e açôes que visassem a instituir reformas urbanas significativas e a favorecer grupos sociais cujos interesses fossem dissonantes daqueles do governo. Nesse contexto, apesar de ter contribuído financeiramente para a construção de milhôes de unidades, a política habitacional centralizada no Banco Nacional de Habitação (BNH) ampliou certas desigualdades, pois o acesso à moradia adequada proporcionado por esse banco muitas vezes deixou de incluir grupos sociais de renda mais baixa, principalmente a parcela da população com rendimentos mensais inferiores a três salários mínimos. A relação entre determinados interesses empresariais, específicos da incorporação que produz edifícios de apartamentos, e os direcionamentos da política pública, edilícia e urbana desse período foi estudada por Anitelli (2010) $)^{2}$.

Os movimentos sociais apresentados no presente artigo somente se estruturaram e reivindicaram mais influência no debate político entre as décadas de 1980 e 1990, após a desestabilização do regime militar. É curioso como o enfrentamento e a repressão das forças policiais do Estado sobre tais movimentos, muito frequentemente com a anuência do sistema judiciário, ainda faz parte, em grande medida, da política brasileira contemporânea vigente. Neste trabalho, partilha-se a ideia de Maricato (2002, p. 180) de que, sem participação social, a implementação de qualquer ação originária do Poder Público se torna inviável, pois, dessa forma, os cidadãos são entendidos como objeto e não como sujeitos: "Partimos do pressuposto de que o plano urbano deve ser a expressão democrática da sociedade, se se pretende combater a desigualdade". Há uma ampliação da esfera de debate ao incluir e legitimar participantes diversos, com seus diferentes e conflitantes pontos de vista.

Escolheu-se, aqui, partir dessa premissa para compreender interesses, compromissos e açóes de movimentos sociais que reivindicam moradia no centro da cidade de São Paulo. Uma forma de situar a existência desses agentes organizados é assumir que eles reivindicam direitos sociais instituídos pela Constituição de 1988 e regulamentados por legislaçôes posteriores ${ }^{3}$. $\mathrm{O}$ acesso à moradia adequada seria o mais elementar dos direitos reivindicados por eles ${ }^{4}$. A natureza e a localização dos investimentos, governamentais ou privados, determinam quem será incluído nos benefícios da aglomeração urbana. O discurso dos líderes desses movimentos por moradia insiste em que a parcela social que eles representam seja incluída nessas benesses, não apenas como consumidora, mas também ouvida sobre a formulação de políticas. Isso fica evidente em diversos documentários já realizados sobre o tema ${ }^{5}$, e tal ponto é o principal espectro abordado neste artigo. Ou seja, novos atores emergiram no processo de redemocratizaçáo do país e, atualmente, póem-se incontestavelmente no debate político, incluindo-se, às vezes sem convite formal ou autorização expressa, na formulação da política habitacional que lhes parece cabível. Isso ocorre, por exemplo, através do ativismo das ocupaçôes ${ }^{6}$ de edifícios deixados ociosos por seus proprietários legais. Mais precisamente, o principal objetivo deste trabalho é compreender de- 
mandas e açôes de movimentos populares por moradia no centro de São Paulo, como a ocupação de edifícios ociosos, e situá-las nas recomendaçôes da legislaçâo vigente, que estabelece a noção de função social da propriedade urbana e indica mecanismos para coibir a especulação imobiliária.

Aspectos da própria legislação urbana brasileira, que consta especialmente do arcabouço jurídico federal, são usados como fonte para situar certos argumentos, por exemplo, a demanda popular por moradia adequada na regiáo central. Esses aspectos podem ser considerados desdobramentos do que os legisladores constituintes denominaram de funçấo social da propriedade urbana - assinale-se que eles serão, neste artigo, entrevistos por meio dos autores consultados. Dessa perspectiva, os procedimentos metodológicos utilizados neste trabalho concentram-se em uma revisão bibliográfica, cujo recorte temático concatena-se com o objetivo principal. Também são feitas referências a documentários com interesses e abordagens diversas, os quais contribuíram, pontualmente, para situar os argumentos observados na bibliografia. Por fim, um caso concreto é apresentado: o edifício São Manuel, ocupado por militantes de movimentos sociais e pessoas em situação de rua e autogerido pelos próprios moradores.

A revisão bibliográfica também se fez no âmbito de uma pesquisa de doutorado (ANITELLI, 2015), concatenada com uma série de viagens acadêmicas a diversas metrópoles brasileiras, o que favoreceu a realização de entrevistas com dezenas de agentes privados do mercado imobiliário e dezenas de visitas técnicas. Os resultados de tal pesquisa apontaram certas contradiçôes entre os interesses dos principais promotores imobiliários, os direcionamentos da política pública e as demandas de populaçóes com renda mais baixa. Nesse contexto, uma das conclusóes é que permanecem relativamente excluídas as famílias que não têm rendimentos mensais suficientes para arcar com os custos do acesso à moradia gerados por esse modelo de produção. Mesmo quando são atendidas pela iniciativa privada ou pelo Poder Público, quase nunca lhes são oferecidas moradias em centralidades consolidadas. Por isso, morar no centro da cidade torna-se praticamente inacessível. Esse quadro contribui para mostrar os equívocos e as contradiçôes que o presente artigo abordará.

\section{ESCONDE-ESCONDE DOS PROBLEMAS HABITACIONAIS: COM NOVAS REGRAS, OS POBRES TAMBÉM PODEM JOGAR}

A própria Constituição vigente, principal marco da redemocratização e da alteração das relaçôes político-sociais no país, no que tange à reforma urbana, foi delimitada a partir de iniciativas populares. Consta que 130 mil cidadãos foram signatários da Emenda Constitucional de Iniciativa Popular pela Reforma Urbana, que resultou nos artigos 182 e 183, intitulados "Da Política Urbana" . Eles abordam, entre outras questôes, a função social da propriedade urbana, prevendo eventuais sançôes no caso de descumprimento da lei. Maricato (2002, p. 174-175) é enfática ao qualificar o objetivo deles: "o controle sobre a propriedade fundiária e imobiliária visando sua função social”. A partir desse novo arcabouço jurídico, a democratização da gestão urbana é fundante, tornando-se central no discurso dos movimentos sociais que lutam por acesso à moradia e a uma forma mais justa de distribuição dos benefícios da
7 Disponível em: <http:// www.planalto.gov.br/ccivil_03/constituicao/constituicao.htm>. Acesso em: 23 jul. 2015. 
8 A própria prefeitura explica: "Tal ociosidade normalmente decorre de atitudes especulativas, quando os proprietários aguardam condições vantajosas financeiramente para comercializálos" (Disponível em: <http://gestaourbana.prefeitura.sp.gov. br/2179-2/>. Acesso em: 23 jul. 2015).

9 Tatagiba, Paterniani e Trindade (2012), referindo-se ao Estatuto da Cidade, confirmam que esses movimentos embasam-se em princípios legais para legitimar suas reivindicações, inclusive a ocupação de imóveis abandonados que, na visão dessas pessoas, estão em desacordo com a lei. cidade. Nessa perspectiva, pode-se concluir que a populaçáo em geral não foi beneficiada de maneira passiva por tal iniciativa da emenda, já que milhares de pessoas ajudaram efetivamente a construir o conceito de função social aplicado ao fenômeno urbano e a criar parâmetros para a ação pública e institucional no território das cidades. Em outras palavras, os participantes não foram apenas objeto, mas sujeitos da ação. A importância dessa emenda é lembrada por diversos autores, entre eles Ferreira (2005) e Rolnik (2009). Portanto, quando ocupam edifícios abandonados, líderes de tais movimentos legitimam juridicamente esse ato recorrendo a princípios da própria legislação brasileira, pois esses imóveis não cumpriam sua função social, já que estavam ociosos, desocupados, sem uso.

Essas ponderaçóes buscam dar legitimidade e amparo a açóes populares que querem discutir reformas urbanas profundas que contrariam, em sua maioria, interesses econômicos e arranjos políticos entre empresários influentes e gestores públicos que alinham suas decisóes em funçáo das demandas daqueles. Aqui, no contexto desse difícil embate, assume-se a importância de se combater a tendência de criminalização da pobreza e de açôes de movimentos populares que reivindicam, a seu modo, suas pautas. A Constituição Federal, primeiramente, se presta a isso. Não resta dúvida de que a legislação adotou posturas progressistas, já que o Estatuto da Cidade, mais de uma década depois, regulamentou instrumentos que coíbem a especulação fundiária e imobiliária, reiterando, com isso, a função social da propriedade urbana. O Imposto Predial e Territorial Urbano (IPTU) progressivo no tempo e o parcelamento, edificação e utilizaçẫo compulsórios são exemplos disso ${ }^{8}$, pois inibem a ociosidade de imóveis, discurso evidentemente endossado pelos movimentos sociais afins.

Pragmaticamente, o que viabiliza a ocupação de um edifício é justamente o fato de ele estar abandonado. Em outras palavras, o que legitima tal ação é o fato de o proprietário do imóvel não cumprir determinaçôes legais? ${ }^{9}$ O que reivindicam os líderes desses movimentos é que a legislação seja plenamente cumprida e que todos os atores envolvidos, inclusive os atuais proprietários dos imóveis, submetam-se a ela. Concomitantemente, as ocupações incitam os poderes públicos instituídos - Executivo, Legislativo e Judiciário - a posicionarem-se sobre a questáo. Isso costuma evidenciar que esses representantes públicos estáo, quase sempre, contrários aos interesses da população mais pobre, haja vista as inexoráveis reintegraçôes de posse. Kowarick (2007, p. 203) aponta os personagens dessas ocupaçóes, seus motivos e justificativas:

[...] os movimentos sociais reivindicam a ocupação destes espaços, apoiados na existência de imóveis vazios, por centenas de milhares de pessoas que moram em cortiços, hotéis, pensóes e apartamentos precários, para não falar naqueles que habitam nas ruas ou em abrigos públicos. Assim, [...] desenvolvem discursos e atuaçóes com base em uma concepção de reforma urbana em função de direitos de cidadania.

Levantamentos confirmam a quantidade significativa de imóveis abandonados na região central. Neste artigo, essas propriedades privadas, passíveis de serem incluídas em políticas públicas voltadas à produção de moradias, são entendidas a partir dos argumentos de Silva (2007, p. 54): "o abandono e a ociosidade dos imóveis na área central constituem um abuso em relação à função social da propriedade. Por outro lado, representam uma oportunidade para uma política de repovoamento com diversidade social [...]”. A autora sugere que mais de 300 edifícios da regiáo não esta- 
riam ocupados adequadamente, entre imóveis privados e públicos ${ }^{10}$, segundo levantamentos de movimentos sociais e da prefeitura de Sáo Paulo ${ }^{11}$. Ela ainda traz outro componente que valoriza a ocupação compulsória desses edifícios abandonados e sua transformação em habitação de interesse social: a grande quantidade de imóveis ociosos com elevadas dívidas de IPTU, algumas acumuladas por anos ou décadas, cujos valores seriam equivalentes ao do próprio imóvel, a exemplo do edifício São Manuel, que será examinado no próximo tópico (Ocupação Marconi). A sonegação desses impostos prejudica, claramente, a implementação de políticas públicas municipais e o atendimento de demandas dos movimentos sociais por moradia, expondo, uma vez mais, a diferença entre recomendaçôes e aplicaçôes da legislação.

A ocupação de um edifício abandonado náo deveria ser justificada apenas por razóes pragmáticas, apesar de fundamentais, como o acesso à moradia adequada. Em grande medida, ao menos nas pretensôes dos militantes mais lúcidos, a ocupação torna-se um mecanismo de ativismo político. É possível associar, por exemplo, ocupaçóes ocorridas a partir dos anos 1990 e o surgimento de discussóes sobre modalidades de financiamento e viabilizaçáo de compra e reforma de imóveis ociosos com o objetivo de produzir habitaçôes de interesse social, realizadas pelo Poder Público local (INSTITUTO PÓLIS, 2009). Alguns autores são taxativos ao afirmar que a possibilidade de requalificação de edifícios vazios "foi inicialmente apontada pelos movimentos sociais atuantes na área central, quando passam a executar um plano de 'ocupaçóes' organizadas, a partir da segunda metade dos anos [19]90” (SILVA, 2007, p. 7$)^{12}$. Nesse caso, esses movimentos populares não apenas reivindicaram a aplicação da legislação disponível, mas também apontaram caminhos alternativos, que foram adotados, ainda que parcialmente, por gestores públicos locais. Por exemplo, um estudo do Instituto Pólis (2009) aponta resultados específicos conquistados a partir da pressão exercida pelos movimentos sociais: reforma de edifícios, construção de novas moradias, locação social e bolsa aluguel.

Esse quadro representa um enorme desafio não somente aos gestores públicos competentes, mas também aos pesquisadores acadêmicos, pois, especificamente nesse caso, o principal estímulo e fonte originária da ideia de reconversóes de edificações abandonadas são parcelas da população desvinculadas dos interesses econômicos dos tradicionais agentes imobiliários privados, com enormes dificuldades em situar-se no debate político já instituído, pessoas normalmente desprovidas de influência sobre a gestão urbana e sem os conhecimentos técnicos necessários. O desafio que se coloca é que os procedimentos metodológicos e as abordagens acadêmicas dos estudos científicos precisam, em alguma medida, abarcar as demandas formuladas por essa populaçáo, e não simplesmente, como muitas vezes acontece, imaginar, a partir do âmbito da academia, soluçóes aparentemente adequadas a esses populares.

Outro aspecto do fenômeno é que não são apenas as ações desses movimentos que costumam, inclusive judicialmente, ser interpeladas, desqualificadas ou desvalorizadas. A área central, território prioritariamente pretendido pela população mais pobre, tem, atualmente, grande descrédito. Reportagens da imprensa de grande circulação e com significativas repercussôes costumam associar a área central à criminalidade, e, com isso, intencionalmente ou não, a associam também à pobreza, já que são pobres que moram majoritariamente em boa parte da região central. Nesse contexto, reitera-se a estratégia de criminalizar a pobreza, ao mesmo tempo que problemas restritos territorialmente são tendenciosamente generalizados, como a venda
10 Ela menciona um edifício, abandonado e ocupado por movimentos de moradia, lo calizado na Rua do Ouvidor, que pertenceria ao governo do estado de São Paulo.

11 Outros estudos também relatam a existência de um significativo número de domicílios vazios no centro, como o Instituto Pólis (2009, p. 10). Em algumas localidades, em específico, a taxa de imóveis vazios superaria os $20 \%$, por exemplo, Sé $(26,8 \%)$ República $(22,7 \%)$ e Pari (21,0\%).

12 É possível entrever esse ativismo político também nas palavras de Castro (2010, p. 3): “As ocupações visam encontrar soluções de moradia para as famílias, mas também denunciar a carência de moradia, enquanto edifícios públicos ou privados se encontram vagos no centro da cidade." 
13 A deterioração é confirmada por Sampaio e Pereira (2003, p. 177): "São Paulo [...] [não escapou] do problema de deterioração de parte de sua área central. [...] Grandes empresas, bancos, comércio de luxo, hotéis, equipamentos de lazer deslocaram-se para outras áreas".

14 Um lugar ao centro. Direção: Fernanda Stica. São Paulo: ECA-USP, 2011 (Disponível em: <https:// www.youtube.com/user/ LugarCentroDoc>. Acesso em: 23 jul. 2015). e o consumo de drogas ou a prostituição. Sem menosprezar a degradação ambiental que, de fato, existe ${ }^{13}$, diversas açôes públicas, com evidentes interferências de empresas do setor imobiliário, têm sido pretendidas na área, a exemplo do projeto Nova Luz (SÃO PAULO, 2011).

Aqui, adverte-se que as políticas de renovação do centro, quando dissociadas dos interesses da população mais pobre e realizadas por uma parceria pública-privada que inclui, como ente privado, apenas empresas capazes de catalisar grandes somas de capital, geram, inadvertidamente, processos de gentrificação. Nesse contexto, os mais pobres não participariam da concepção da renovação urbana e, como não teriam rendimentos suficientes para consumir o que seria futuramente oferecido, também não seriam beneficiários dos resultados e, provavelmente, nem mesmo habitariam o centro, uma vez concluído o processo de renovação. Essas questôes estão implícitas, de diversas formas, em Kowarick (2007) e Tatagiba, Paterniani e Trindade (2012). Isso significa que o direito à moradia adequada também implica direito à cidadania, pois o acesso aos benefícios da região central, principalmente após grandes reformas urbanas, pressupóe acesso e proximidade a serviços de saúde, de cultura, oportunidades de trabalho, de mobilidade etc. Mostra-se, portanto, bem amplo o espectro de leis em que esses movimentos populares podem se apoiar para reivindicar seus direitos. Como os representantes dos movimentos sociais não costumam participar de círculos acadêmicos, documentários realizados sobre esses movimentos (muitas vezes pelos próprios participantes) tornam-se uma importante fonte de informação. Um filme, com o sugestivo nome de Um lugar ao centro ${ }^{14}$, aborda possíveis repercussóes do projeto Nova Luz a partir da opinião de moradores da regiáo, participantes de organizações não governamentais (ONGs) e de associaçôes diversas. Todos eles, sem exceção, se posicionam contrários ao projeto, nos termos colocados. Todos reivindicam maior influência sobre a concepçáo do projeto e temem ser desalojados se os rumos das intervençóes não se alterarem. É possível resgatar o comentário de Maricato (2002) de que uma ação pública qualquer, para dotar-se de legitimidade, precisa considerar fundamentalmente a população atingida como sujeito ativo do processo, e não unicamente como objeto da ação. Esse seria um caso concreto de parcelas significativas da população da região central que pretendem alterar os objetivos do Poder Público porque não participaram da formulação das ações.

Isso tem ocorrido em diversas outras metrópoles brasileiras. Alguns sintomas são detectáveis em todos os casos (ANITELLI, 2015): renovaçôes urbanas significativas, em amplos territórios, em centralidades consolidadas, muitas vezes próximas da região central da cidade; conivência do Poder Público com interesses econômicos de agentes imobiliários privados que têm protagonismo nessas renovaçóes, pois incorporam, constroem e vendem seus produtos na área da renovação; exclusão de parcelas mais pobres da população da concepção da intervenção urbana e de seus eventuais benefícios futuros; exclusão, até mesmo, dos produtos acima mencionados; produtos imobiliários oferecidos posteriormente pelo mercado privado, como apartamentos em edifícios destinados a parcelas da população com renda mais alta, que passam a frequentar a região após (e apenas se) a renovação se efetuar nos termos aqui expostos; desqualificação de preexistências edilícias, urbanas, ambientais, paisagísticas e dos próprios usos (comércio, serviços, moradia, etc.) característicos da região antes da intervenção; expulsão de populaçôes mais pobres, não consumidoras dos produtos comerciais, educacionais, culturais, entre outros - que serão oferecidos pela iniciativa 
privada em geral, e não apenas pelo mercado imobiliário, após a renovação. Além disso, não é demais lembrar o generalizado apoio financeiro de empresas do setor imobiliário, como incorporadoras, construtoras e empreiteiras, para a campanha eleitoral de políticos eletivos municipais, como vereadores e prefeitos. O risco é que esses vultosos capitais venham a comprometer e enviesar o trabalho dos eleitos, que, nessas condiçóes, tenderiam a beneficiar, prioritariamente, as empresas que contribuíram com recursos financeiros para elegê-los.

É importante concluir que a população, organizada ou não, que se posiciona de forma contrária a essas renovações urbanas, se opóe também, intuitiva ou deliberadamente, ao modelo de negócio descrito acima. Alguns casos exemplificam essa oposição, como o empreendimento imobiliário privado Novo Recife, no bairro São José, área central da cidade de Recife, Pernambuco, que gerou o movimento popular contrário Ocupe Estelita, referindo-se ao nome do antigo cais localizado em uma regiāo atualmente mantida ociosa pelos proprietários dos imóveis, onde ele pretensamente seria implantado. Novamente, documentos audiovisuais, como o documentário Recife, cidade roubada ${ }^{15}$, veiculados através da Internet, são rápidos e eficientes em registrar e analisar os interesses desses movimentos sociais, a partir de outras abordagens e opiniōes. Outro caso notável é a Operação Urbana (OU) Consorciada Nova BH, prevista para contemplar boa parte do território de Belo Horizonte, Minas Gerais. Uma audiência pública, realizada na cidade, em 20 de novembro de 2013, nas dependências do Conselho Regional de Engenharia e Agronomia (CREA) local, teve grande adesão de diversos movimentos populares. Todas as pessoas que se manifestaram na tribuna, sem exceção, se posicionaram contra a OU nos termos colocados pelo Poder Executivo. As justificativas desses cidadãos, tanto na audiência pública sobre a Nova $\mathrm{BH}$ quanto nas reaçôes que deram origem ao Ocupe Estelita, escancaram os sintomas listados no parágrafo anterior ${ }^{16}$. O que fica inevitavelmente implícito nessas declaraçóes é o descumprimento, na opinião de quem se manifesta, de recomendaçôes da legislação que indicam políticas públicas urbanas mais democráticas em seu processo e mais abrangentes em seus resultados. Políticas que sejam mais inclusivas e que considerem populaçóes com um espectro socioeconômico mais amplo e, prioritariamente, as que têm menor rendimento.

Tais reaçôes populares são aqui entendidas como uma tentativa de parcelas da sociedade civil de participar mais plenamente do debate político sobre a elaboração e a gestão de importantes materialidades urbanas. É necessário frisar que esse debate sempre existiu e que certos atores, como setores empresariais da construçáo civil, sabidamente atuaram de modo a ter seus interesses contemplados, a alinhar as açôes do Poder Público em função desses interesses e a restringir a atuação de outros atores, pertencentes a outros círculos sociais, cujos interesses seriam, eventualmente, distintos ou mesmo contrários aos desses empresários. A verticalização urbana atual, principalmente a que decorre de vínculos com o capital financeiro, realizada a partir da ação de incorporadores imobiliários em centenas de bairros de população de renda baixa, média e alta, em metrópoles de todas as regiôes brasileiras, é um exemplo concreto dos interesses desses empresários materializados na metrópole, com a conivência dos gestores públicos competentes (ANITELLI, 2015) ${ }^{17}$. Portanto, a partir desse diagnóstico, o que esses movimentos populares objetivam não é tanto criar um embate, mas, sobretudo, participar do debate político do qual eles foram historicamente excluídos, impondo suas pautas. No caso dos movimentos por moradia no centro
15 Recife, cidade roubada Direção: Ernesto de CarvaIho, Leon Sampaio, Luís Henrique Leal, Marcelo Pedroso e Pedro Severien. Recife, 2014 (Disponivel em: <https://www.youtube.com/ watch? $v=d J Y 1 X E 2 S 9 P k>$. Acesso em: 24 jul. 2015).

16 Outras manifestações do gênero, que ocorreram nas mesmas circunstâncias, podem ser mencionadas, como o Ocupe Augusta, em São Paulo, o Ocupe Mauá, em Porto Alegre, e o Ocupa Golfe, no Rio de Janeiro.

170 autor estudou essa produção imobiliária em cinco metrópoles brasileiras: Recife, Porto Alegre, Belém, Goiânia e Belo Horizonte. 
18 Realizada entre 15 e 17 de maio de 2009, em São Paulo, no 110 Encontro Estadual de Moradia Popular, organizado pela União dos Movimentos de Moradia (UNM). de São Paulo, a ação mais vigorosa e exuberante e, ao mesmo tempo, controversa é a ocupação de edifícios abandonados por seus proprietários.

Essa ação radical não é unânime nem mesmo entre os membros dos movimentos. Uma pesquisa de opiniáo realizada por Tatagiba, Paterniani e Trindade (2012, p. $402)^{18}$ mostra que, dos respondentes, cerca de um terço (32\%) é contrário às "festas", como são nomeadas por eles as ocupaçôes. A principal justificativa deles (34\%) é que elas são violentas e perigosas. É evidente que a reação armada e militarizada das forças de segurança do estado de Sáo Paulo, muitas vezes desproporcional e unilateral, já comentada aqui, influenciou o receio exposto nessas respostas. Os próprios autores (2012, p. 413) confirmam essa prática e a criação de estereótipos: "A criminalização dos movimentos sociais, ao lado da criminalização da pobreza, tem sido uma prática recorrente das administraçóes municipais que se sucederam desde 2005 [...], com reintegraçôes de posse violentas e repressóes truculentas". É óbvio que a ocupação, em si, é apenas um aglutinador que permite, aos seus participantes, para além da edificação ocupada e do medo da violência oficial do Estado, ampliar a noção de cidadania e de ativismo político.

A mesma pesquisa aponta que cerca de dois terços dos respondentes consideram os movimentos de moradia como meio de "consciência política, maior conhecimento dos direitos, maior sensibilidade para questóes sociais e da política habitacional" (49,7\%) ou de "crescimento pessoal, autoconfiança, autoestima, esperança" (19,1\%) (TATAGIBA; PATERNIANI; TRINDADE, 2012, p. 419, grifo nosso). Pode-se concluir que esses acomunados conhecem melhor seus direitos sobre a cidade que habitam e ampliam seu conhecimento sobre as possibilidades de acesso à moradia adequada, as recomendações da legislação e as políticas habitacionais possíveis. Idealmente, adquirem um nível de organização que permite a seus líderes reivindicar, no debate sobre a reforma urbana, influência proporcional aos sindicatos e a outras organizaçóes empresariais da área, como o Sindicato das Empresas de Compra, Venda, Locação e Administração de Imóveis Residenciais e Comerciais (SECOVI) ou o Sindicato da Indústria da Construção Civil (SINDUSCON). Da mesma forma, eles estariam melhor preparados e amparados para reivindicar assento e frequentar instâncias desse debate, como conselhos populares de política urbana, reuniôes sobre orçamento participativo, audiências públicas, discussóes sobre o Plano Diretor etc. Os constrangimentos postos por uma conjuntura desfavorável não diminuem o ímpeto dessas populaçóes de exigir os direitos que lhes pareçam cabíveis, nem alteram a noção de solidariedade que funda a ação desses movimentos sociais.

Como ponto central aos objetivos deste artigo, reitere-se que, quando lhes é permitido intervir abertamente no debate político, esses movimentos sociais introduzem um elemento a mais na discussão: não apenas o acesso à moradia adequada é requerido, mas também o direito de morar e usufruir do centro da cidade. Essa seria uma novidade, principalmente se comparada com as intervenções público-privadas recentes, cujos protagonistas - e beneficiários - são empresas da construção civil que movimentam grandes somas de capital, pois os produtos oferecidos posteriormente costumam priorizar faixas de renda média e alta. Pouquíssimas vezes incluem rendas baixas, raramente se localizam no centro e quase nunca preveem faixas de 0 a 3 salários mínimos. Portanto, moradia no centro para famílias realmente pobres não estaria incluída nem na agenda de políticas públicas nem de negócios privados. Essa situação, ao mesmo tempo que complexifica e isola os movimentos sociais e expóe 
o enorme desafio, mostra igualmente o quão importante é a pauta desses cidadãos, que dependem, em grande medida, do próprio esforço para se verem representados.

Os benefícios de morar na região central são incontestáveis. Um dos principais é a diminuição dos desgastes físicos e mentais ocorridos por causa de deslocamentos diários pendulares periferia-centro-periferia, a redução dos custos com mobilidade e o acesso a fartas opçóes de transporte coletivo ${ }^{19}$. O centro também contém maior quantidade e diversidade de serviços públicos, equipamentos urbanos e, evidentemente, maior concentração de postos de trabalho ${ }^{20}$, formais e informais ${ }^{21}$, oferecidos nas propriedades privadas ou no espaço público, incluindo ambulantes e camelôs, sendo boa parte desses serviços, equipamentos e empregos acessíveis com pequenos deslocamentos, muitas vezes a pé. Essas questôes são pontualmente constatadas por diversos autores (KOWARICK, 2007; INSTITUTO PÓLIS, 2009; CASTRO, 2010; TATAGIBA; PATERNIANI; TRINDADE, 2012).

Um dos movimentos socioterritoriais mais significativos da história brasileira foi a migração rural-urbana que ocorreu entre os anos 1940 e 1980 (ROLNIK, 2009). É sabido que grande parte dessa migração originou-se no Nordeste do país com destino ao Sudeste, principalmente para o Rio de Janeiro e Sáo Paulo, suas maiores metrópoles. Sabe-se, também, que é grande a probabilidade de que um dos primeiros empregos dessa população deslocada ocorra em canteiros de obras da construção civil ${ }^{22}$, cujos salários da mão de obra pouco qualificada, sem formação específica, sempre estiveram entre os mais baixos do mercado de trabalho. Geraçôes de migrantes nordestinos teriam, assim, ajudado a construir boa parte dos edifícios de apartamentos da capital paulista a partir de meados do século XX, apesar de quase nunca os habitarem. Como resultado, pode-se gerar uma alienação sobre as regiôes consolidadas da cidade, visto que, apesar dos serviços prestados como serventes, pedreiros etc., eles raramente usufruem do ambiente construído como moradores e pouco o frequentam como consumidores. A moradia dos mais pobres, incluindo boa parte dos migrantes, localizava-se em centros menos consolidados ou regióes periféricas, áreas que não interessavam comercialmente ao mercado imobiliário, muitas vezes vinculadas a restrições da legislação urbanística e ambiental que não permitiam a construção de edificaçôes.

Esse processo, cujo principal resultado são periferias precárias e populosas, foi concomitante, contraditoriamente, ao esvaziamento populacional de regiōes centrais consolidadas, intensificado nas últimas décadas (INSTITUTO PÓLIS, 2009)²3. O Poder Público contribuiu de várias formas para esse fenômeno do crescimento periférico ou, em outras palavras, para a periferização da pobreza. Uma dessas formas é a prioridade quase total para a construção de conjuntos habitacionais acessíveis a populaçôes de baixa renda na periferia, longe do centro. Até o final dos anos 1990, a produção dos governos municipal e estadual priorizava essa postura (SILVA, 2007). A produção imobiliária privada, apoiada - e, quase sempre, viabilizada, inclusive em termos financeiros - pelo Poder Público, não foi menos significativa. Porém, igualmente, a incorporação imobiliária, quando atendia essa faixa de renda, construía habitações para os mais pobres, quase exclusivamente, em regiōes periféricas (ANITELLI, 2015). Conclui-se, assim, que as açôes públicas - e privadas -, cujos objetivos eram o acesso à moradia para pessoas com menos dinheiro na sociedade brasileira, nos últimos anos, contrariam grandemente os interesses dos atores sociais que efetivamente as representam, os movimentos por moradia no centro.
19 Existiriam, no centro de São Paulo, mais de 250 linhas de ônibus e 7 estações de metrô e trens metropolitanos (INSTITUTO PÓLIS 2009, p. 12).

20 Como exemplo, em 2006 , apenas o distrito da Sé abrigava $16,61 \%$ do total de empregos no município de São Paulo. Além disso, a média de remuneração mensal na região central seria de $\mathrm{R} \$$ 1.344,48 em 2009, indicando que eles seriam relativamente pobres (INSTITUTO PÓLIS, 2009, p. 11, 13).

21 Há uma estimativa, relativamente recente e que ainda deve refletir o quadro atual, de que existem cerca de 10 mil ambulantes e 2 mil catadores de lixo no centro de São Paulo (KOWARICK, 2007, p. 173-174).

22 Mais informações sobre a situação de trabalhadores em grandes canteiros de obra podem ser encontradas em Maricato (1984)

23 Outros autores confirmam a perda de população das áreas centrais, como Silva (2007). 
24 Os vínculos atuais entre os mercados imobiliário e financeiro e as repercussões sobre a produção habitacional brasileira podem ser entrevistos nos argumentos de diversos autores, como Shimbo (2010) e Fix (2011)
$\mathrm{Na}$ instância federal, por exemplo, o governo congregou boa parte dessas açôes nos desdobramentos do Programa Minha Casa, Minha Vida (MCMV). Alguns dos mais influentes empresários do setor da construção civil no país contribuíram para formatar tal programa, enviesando suas metas em função de seus próprios interesses econômicos. Dessa forma, os maiores beneficiados foram os próprios empresários, que lucraram proporcionalmente ao porte técnico-administrativo das empresas e à capacidade de produzir habitaçôes em menor tempo. A imensa maioria das milhares de unidades habitacionais em edifícios de apartamentos construídos nas principais regiōes metropolitanas brasileiras por incorporadores imobiliários, muitas vezes, vinculadas ao mercado financeiro ${ }^{24}$, foi financiada, aos consumidores, com recursos oriundos de fundos estatais, principalmente do MCMV. Como indica Anitelli (2015), a quase totalidade das moradias construídas nessas condiçóes e destinadas a faixas de renda mais baixa localiza-se em periferias distantes, muitas vezes a dezenas de quilômetros do centro - longe, portanto, dos principais benefícios que a região central tem para quem mora nela.

Associado a essas questôes, está o interesse econômico de quem incorpora esses edifícios em construir grande quantidade de unidades habitacionais, em tempo relativamente curto, fato que geraria, a partir de demandas advindas do mercado financeiro, os lucros necessários, adequados ao modelo de negócio instituído. A produção, nesses termos, somente seria possível em regiôes periféricas, muitas das quais pouco urbanizadas ou desabitadas, com grandes glebas de terrenos, adequados para a massiva implantação de megaempreendimentos padronizados. Esses aspectos reforçam o desinteresse de tais empresários em investir seus recursos financeiros na regiáo central da cidade, praticamente já ocupada e quase sem terrenos disponíveis. Desinteressam-se, principalmente, pela reabilitação de edifícios ociosos, já que as moradias resultantes não atenderiam suas solicitações. Como consequência, é provável que eles percam também seus investidores - e os respectivos recursos - oriundos do mercado financeiro, já que não poderiam produzir no ritmo e na quantidade esperada. Os métodos construtivos seriados normalmente utilizados em conjuntos habitacionais construídos na periferia também seriam incompatíveis, uma vez que os diferentes edifícios reabilitados demandariam, em tese, soluçóes construtivas e projetuais específicas, pois se encontram em estados de conservação muito variados. Em outras palavras, não seria mais possível executar projetos padronizados, que são a regra nos conjuntos periféricos.

Nesse contexto, torna-se difícil alinhar, por um lado, interesses de movimentos populares que reivindicam moradia adequada na regiáo central e, por outro lado, políticas públicas cujos resultados são grandes conjuntos habitacionais localizados em periferias urbanas. Esses interesses e políticas tornam-se ainda mais desalinhados com a inclusão dos agentes imobiliários envolvidos. A conclusão é a de que as intençóes dos movimentos por moradia em fixar sua residência no centro contrariam frontalmente um dos fundamentos do programa governamental Minha Casa Minha Vida: a primazia da iniciativa privada envolvida em escolher quais produtos oferecer, onde implantá-los e a quem destiná-los, explorando livremente as rendas fundiárias e imobiliárias. Nas circunstâncias atuais, apoiado pela administração pública, um dos principais pilares da produção imobiliária privada é a especulação.

Portanto, a decisão dos gestores públicos competentes em incluir as demandas desses movimentos sociais pressuporia uma significativa revisão das políticas habitacionais da última década. Isso dimensiona o desafio posto a seus principais líderes, já 
que suas reivindicaçôes, quando atendidas, podem significar o prejuízo de centenas de promotores imobiliários, que têm historicamente exigido prioridade na alocação de recursos públicos. Se esse quadro indica dois polos diferentes, é importante entender como políticos elegíveis se posicionariam diante desse cenário, pois boa parte dos membros dos poderes Executivo e Legislativo municipais tem, como já mencionado, suas campanhas eleitorais fortemente financiadas por setores empresariais da construção civil. A dúvida é se eles estariam dispostos a contrariar interesses dos agentes imobiliários cujo aporte financeiro foi decisivo para a vitória deles nas eleiçôes. Em outras palavras, enquanto o poderio econômico de determinados agentes privados for condicionante de açóes da administração pública, os movimentos populares por moradia terão pouca interferência nos direcionamentos da gestão edilícia e urbana. Os termos que definem a moradia essencialmente como produto imobiliário deveriam ser revistos, nesse contexto.

\section{DESOCUPAR PRECONCEITOS, OCUPAR EDIFÍCIOS: EDIFÍCIO SÃO MANUEL, MAS PODEM ME CHAMAR DE OCUPAÇÃO MARCONI}

Um caso específico será examinado na sequência. Suas qualidades refletem dezenas de outras ocupaçóes de edifícios ociosos no centro de São Paulo ${ }^{25}$ ou de outras metrópoles brasileiras. Trata-se do edifício São Manuel ${ }^{26}$, localizado na Rua Marconi, na esquina da Rua Barão de Itapetininga, distrito da República, centro de Sáo Paulo. Uma forma de situar os atos e as demandas dos ocupantes, visíveis nos relatos a seguir, é assumir a inadequação das políticas públicas locais voltadas ao acesso à moradia, de acordo com as expectativas desses moradores (TATAGIBA; PATERNIANI; TRINDADE, 2012). Esses atos e demandas também refletem as análises já realizadas no tópico anterior, principalmente a incapacidade do Poder Público em produzir moradia adequada suficiente, destinada a faixas de renda baixa e localizada na área central da cidade (ANITELLI, 2015). Apontam, igualmente, para a ineficiência da administração pública em coibir a especulação imobiliária e em exigir, nos termos da legislação vigente, o cumprimento da função social da propriedade urbana (SILVA, 2007). No caso desse edifício, por exemplo, haveria uma significativa dívida em IPTU no valor de 520 mil reais ${ }^{27}$, além, evidentemente, do fato de o imóvel encontrar-se ocioso até a data dessa ocupação.

A Ocupação Marconi ${ }^{28}$ apenas reflete, portanto, as dificuldades de boa parte das famílias pobres urbanas em inserir-se como beneficiárias das possibilidades disponíveis no centro, ao mesmo tempo que demostra, uma vez mais, a desigualdade social existente no Brasil. Uma faixa instalada na porta de entrada do edifício expóe alguns sintomas dessa contradição: "Nós do MMPT [Movimento de Moradia para Todos ${ }^{29}$, que coordena essa ocupação] estamos lutando para o poder público desapropriar os latifúndios improdutivos e acabar com a especulação imobiliária" ${ }^{30}$. As informaçóes a seguir foram obtidas a partir de notícias publicadas em jornais de grande circulação ou de reportagens de outras mídias, como artigos ou vídeos disponibilizados em websites da Internet. Elas tratam da Ocupaçáo Marconi e expressam a opiniáo de alguns moradores entrevistados. As principais coincidências dos perfis socioeconômicos, como sugere o italiano Manuel Moruzzi, coordenador do MMPT e coabitante
25 Como uma ocupação realizada em edifício localizado na Rua Mauá, 340, bairro da Luz, centro da cidade de São Paulo.

26 Projetado nos anos 1930 por Jacques Pilon, que também teria projetado vários outros edifícios localizados na Rua Marconi na mesma época (Disponível em: $<$ http://au.pini.com.br/arquitetura-urbanismo/176/ arquiteto-empreendedor-116503-1.aspx>. Acesso em: 6 ago. 2015).

27 Segundo uma reportagem publicada no jornal O Estado de São Paulo. A referência completa desse texto encontra-se no final deste trabalho, em Zanchetta (2013).

280 edifício São Manuel esteve vazio até 2009, ano em que ocorreu a ocupação (PGM-USP, 2013).

29 Mais informações sobre o MMPT estão atualmente disponíveis em: <http:// www.mmpt.com.br>. Acesso em: 20 fev. 2016.

30 Disponível em: <https:// www.youtube.com/watch?$\mathrm{v}=\mathrm{GYk} 1 \mathrm{f} 7 \mathrm{xrpMo}>$. Acesso em: 6 ago. 2015. 
31 A mesma reportagem menciona que a origem dos moradores é bastante diversa: França, Marrocos, Haiti, Colômbia, Peru, Nordeste, Sul, Amazonas, São Paulo, entre outros lugares.

32 Para a manutenção do edifício, no entanto, é cobrada uma taxa de 30 reais por semana (PGM-USP, 2013).

33 Além dessas, cerca de 100 famílias estariam na fila de espera por eventuais apartamentos vagos. Dados do próprio MMPT mencionam mais de 350 moradores (MMPT, 2013), insinuando, com isso, que seriam grupos domésticos pequenos, com aproximadamente 2 membros por apartamento ocupado.

34 A cozinha comunitária serviria diariamente cerca de 100 refeições no almoço e 200 refeições no jantar (PGM-USP, 2013).

35 Outra atividade relacionada com a segurança alimentar dos moradores são as hortas, construídas nas sacadas dos apartamentos (ZANCHETTA, 2013).

36 São realizadas diariamente duas horas de atividades coletivas, por exemplo, as funções de porteiro, encanador, pintor, professor, entre outras (ZANCHETTA, 2013). do edifício, são a renda baixíssima, concentrada entre 0 e 3 salários mínimos, e a predominância do trabalho informal (PGM-USP, 2013) ${ }^{31}$.

Preferiu-se utilizar o termo "coabitante do edifício" e não "habitante do apartamento", pois, aparentemente, esses moradores suscitaram outros significados do morar, já que parte do cotidiano dessas pessoas é realizada coletivamente, com a ajuda voluntária, muitas vezes não remunerada ${ }^{32}$, dos vizinhos. A própria noção de privacidade altera-se na medida em que a convivência diária é ampliada. São várias atividades, realizadas conjuntamente por cerca de 170 famílias (ZANCHETTA, 2013) ${ }^{33}$ : cozinha comunitária ${ }^{34}$, padaria artesanal ${ }^{35}$, creches para as crianças, aulas de reforço escolar para os estudantes, cinema com diferentes sessóes destinadas aos públicos infantil e adulto etc., que, segundo as pretensóes do MMPT (2013), seriam uma usina de ideias e experimentações sociais de coletividade. Essas atividades comunitárias, realizadas nas áreas coletivas do edifício, contribuem para diminuir bastante os gastos mensais desses moradores, cujos rendimentos são sabidamente insuficientes. Como são serviços que não visam ao lucro daqueles que os empreendem, seus custos são muito menores do que aqueles praticados no mercado privado. O principal exemplo talvez sejam as duas refeiçóes diárias oferecidas por e para os moradores, custando apenas 10 reais por semana, por pessoa (PGM-USP, 2013). Nesse contexto, são revistas as formas de consumo normalmente encontráveis numa sociedade capitalista típica. As pessoas são induzidas a cuidar das áreas comuns adjacentes ao espaço privativo ocupado por sua família, sendo, reciprocamente, ajudadas pelos demais habitantes do prédio ${ }^{36}$.

Assume-se aqui que a autogestão descrita não ocorreria apenas por falta de recursos financeiros para contratar terceiros e constituir um condomínio tradicional, mas também pela intenção dos moradores em decidir coletivamente sobre seu próprio cotidiano doméstico. Apropriando-se dos termos apontados anteriormente por Maricato (2002), os moradores que possuem essa consciência são sujeitos e não apenas objeto da ação alheia, já que assumem protagonismo sobre o funcionamento do edifício. Essa postura pode gerar leituras mais críticas sobre a política habitacional local adotada por gestores públicos, quando ela destoar dos interesses dessas pessoas. Pode gerar também maior interesse em participar da concepção dessas políticas, ao exigirem a democratização da gestão urbana, como apontado na Constituição (FERREIRA, 2005; ROLNIK, 2009).

Constituem-se atividades realizadas pelos próprios moradores, sem a participação, interferência ou conivência de agentes públicos ou privados. Exatamente por isso, a rotina dessas pessoas é completamente diferente do comum. Atualmente, no Brasil, nenhum programa público ou produto privado oferece um edifício de apartamentos com tais serviços, autogeridos pelos próprios moradores, sem interferências externas. O próprio programa habitacional e as tipologias arquitetônicas poderiam ser repensados nessas circunstâncias. Se a vivência da Ocupação Marconi pode ser tomada como uma alternativa razoável para famílias com parcos rendimentos mensais, o significado do termo "edifício de apartamentos" deve ser redefinido. Mais do que isso, na medida em que os arquitetos são responsáveis pela definição desses termos e de seu respectivo programa, cabe indagar se a formaçáo desses profissionais os torna realmente aptos a abarcar essas formas alternativas de provisão de moradias. 


\section{CONCLUSÕES}

Uma importante constatação é a de que os discursos, as açóes e os interesses dos variados grupos sociais ou econômicos quase nunca estão plenamente alinhados entre si, além de contradizerem, eventualmente, determinaçôes da legislação vigente. Esses conflitos exigem que a administração pública escolha quais políticas habitacionais e urbanas adotar, assumindo que, em função dessa decisão, certos grupos serão privilegiados e outros prejudicados. Sem a intermediação do Estado, cresce a chance de parcelas desfavorecidas economicamente serem oprimidas por grupos empresariais que movimentam grandes somas de capital. Nesse contexto, parece fundamental que os gestores públicos competentes tenham sensibilidade e competência para, em um processo democrático, abarcar, em suas políticas, os diversos interesses da sociedade brasileira e, fundamentalmente, das famílias mais pobres, majoritárias nas metrópoles brasileiras. Some-se a isso, a necessidade de se compatibilizar os legítimos interesses econômicos dos agentes empresariais do setor da construçáo civil com os anseios mais urgentes dos movimentos populares que reivindicam seu lugar no centro. Mais precisamente, o interesse econômico de tais empresários precisa ser compatível com os interesses de uma política pública, efetivamente democrática, que não exclua de seus atos parcelas da população sem a mesma capacidade financeira e a mesma influência política desses empresários.

Nesse cenário, o que se configura é a ampliação dos atores que participam do embate político sobre a reforma urbana e o direito à moradia adequada e à própria cidade. Atualmente, como visto, uma das formas mais transgressoras e controversas de movimentos populares por moradia reivindicarem participação nesse embate é a radical decisão de ocupar um imóvel ocioso, sem uso adequado, mas que legalmente pertence a outra pessoa. Isso suscita outra constatação, que pode ser justificada a partir das relaçóes entre gestores públicos e agentes imobiliários, relaçóes nem sempre lícitas: a legislação não é aplicada com o mesmo rigor em todas as circunstâncias. Conclui-se que o Judiciário aplica mais fácil e recorrentemente o direito de reintegração de posse do que, por exemplo, a punição de ilegalidades cometidas pelos proprietários dos imóveis, como a inobservância da função social da propriedade urbana ou eventuais dívidas milionárias com as prefeituras. Essa seria mais uma faceta das contradições discutidas neste artigo e resgatadas no parágrafo anterior. Muito além das ocupaçôes dos edifícios abandonados, essa população, que exige ser incluída no planejamento das materialidades urbanas, deveria poder influenciar na concepção, na gestấo, nas revisóes e nas atualizaçóes da política pública habitacional na mesma proporção e com a mesma importância dos demais agentes envolvidos.

Por fim, algumas das ocupaçóes, "festas" nas palavras dos ocupantes, estabelecem outros significados ao convívio cotidiano entre os moradores, exigindo, de cada um, participação em atividades coletivas cujos beneficiários são eles próprios. Essas atividades envolvem serviços domésticos básicos, como creche para as crianças e cozinha comunitária, criando outras formas de resolver demandas diárias essenciais. $\mathrm{O}$ que se provoca aqui é que, como as pessoas moram de outra maneira, por consequência, nesses casos, o espaço arquitetônico proposto poderia ser repensado, bem como o programa habitacional e a tipologia da edificação. Mais do que isso, se as resultantes arquitetônicas podem alterar-se, o modelo de provisão habitacional também deveria 
Felipe Anitelli é arquiteto e urbanista pelo Centro Universitário Barão de Mauá (CBM); mestre e doutor em Arquitetura e Urbanismo pelo Instituto de Arquitetura e Urbanismo da Universidade de São Paulo (IAU/USP); pós-doutorando na Faculdade de Arquitetura e Urbanismo (FAU) da USP.

E-mail:felipeanitelli@yahoo. com.br.

Marcelo Tramontano é arquiteto e urbanista pela Pontifícia Universidade Católica de Campinas; mestre em Architecture en Terre pela Ecole D'Architecture de Grenoble; doutor em Arquitetura e Urbanismo pela Faculdade de Arquitetura e Urbanismo da Universidade de São Paulo (FAU/USP); professor associado no Instituto de Arquitetura e Urbanismo (IAU) da USP.

E-mail: tramont@sc.usp.br.

Artigo recebido em 31 de agosto de 2015 e aprovado para publicação em 9 de abril de 2016. ser revisto. As questóes recuperadas nesse parágrafo estáo fundamentadas no protagonismo dos participantes de certas ocupaçóes, reivindicando o direito de requalificar o espaço existente que, nesses termos, passa a ser autogerido. Conclui-se que essa postura é bastante inovadora, se comparada à passividade com que normalmente são tratados os consumidores de produtos imobiliários oferecidos tanto pelo mercado privado quanto pela provisão pública. Diante desse quadro, pode-se inferir que o ativismo político de muitos integrantes desses movimentos populares altera significativamente os termos em que são entendidos a produção e o consumo de moradias, ao menos em áreas centrais metropolitanas.

\section{REFERÊNCIAS}

ANITELLI, F. Como nasce um modelo: o projeto de apartamento na cidade de Sáo Paulo. 2010. Dissertação (Mestrado em Arquitetura e Urbanismo) - Instituto de Arquitetura e Urbanismo, Universidade de São Paulo, São Carlos, 2010.

- [Re]produção?: repercussóes de características do desenho do edifício de apartamentos paulistano em projetos empreendidos no Brasil. 2015. Tese (Doutorado em Arquitetura e Urbanismo) - Instituto de Arquitetura e Urbanismo, Universidade de São Paulo, São Carlos, 2015.

CASTRO, C. O centro velho e a moradia: requalificação urbana em São Paulo. In: CONGRESSO LUSO-BRASILEIRO PARA O PLANEJAMENTO URBANO, REGIONAL, INTEGRADO, SUSTENTÁVEL, 4., 2009, Faro. Anais do IV Congresso Luso-Brasileiro para o Planejamento Urbano, Regional, Integrado, Sustentável. Faro: Universidade do Algarve, 2010. p. 1-12. Disponível em: <http://pluris2010.civil. uminho.pt/Actas/PDF/Paper163.pdf>. Acesso em: 20 jul. 2015.

FERREIRA, J. S. A cidade para poucos: breve história da propriedade urbana no Brasil. In: SIMPÓSIO INTERFACES DAS REPRESENTAÇŌES URBANAS EM TEMPOS DE GLOBALIZAÇÃO, 2005, Bauru. Anais do Simpósio Interfaces das representaçóes urbanas em tempos de globalização. Bauru: UNESP/SESC, 2005. p. 1-20. Disponível em: <www.fau.usp.br/docentes/depprojeto/j_whitaker/propurbcred.doc>. Acesso em: 10 jul. 2015.

FIX, M. A. B. Financeirização e transformaçōes recentes no circuito imobiliário no Brasil. Tese (Doutorado em Desenvolvimento Econômico) - Instituto de Economia, Universidade Estadual de Campinas, Campinas, 2011.

INSTITUTO PÓLIS. Moradia é central: inclusão, acesso e direito à cidade. São Paulo: Instituto Pólis, 2009.

KOWARICK, L. Áreas centrais de São Paulo: dinamismo econômico, pobreza e políticas. Lua Nova, São Paulo, n. 70, p. 171-211, 2007. Disponível em: <http://www.scielo.br/ scielo.php?pid=S0102-64452007000100008\&script=sci_arttext $>$. Acesso em: 14 jul. 2015.

MARICATO, E. Indústria da construçâo e política habitacional. 1984. Tese (Doutorado em Arquitetura e Urbanismo) - Faculdade de Arquitetura e Urbanismo, Universidade de São Paulo, São Paulo, 1984.

As ideias fora do lugar e o lugar fora das ideias: planejamento urbano no Brasil. In: ARANTES, O.; VAINER, C.; MARICATO, E. A cidade do pensamento único: desmanchando consensos. Petrópolis: Vozes, 2002. p. 121-192.

MMPT. Os rumos da Ocupa Marconi. MMPT, São Paulo, 15 dez. 2013. Disponível em: <http://www.mmpt.com.br/os-rumos-da-ocupa-marconi/>. Acesso em: 6 ago. 2015. 
PGM-USP. Reportagem sobre a Ocupação Marconi, ocorrida no edifício São Manuel, localizado no centro de São Paulo. TV USP ONLINE, 13 set. 2013. Disponível em: <https:// www.youtube.com/watch?v=GYk1f7xrpMo>. Acesso em: 6 ago. 2015.

ROLNIK, R. Democracia no fio da navalha: limites e possibilidades para a implementação de uma agenda de reforma urbana no Brasil. Revista Brasileira de Estudos Urbanos e Regionais, São Paulo, v. 11, n. 2, p. 31-50, nov. 2009. Disponível em: <http://unuhospedagem.com.br/revista/rbeur/index.php/rbeur/article/view/219>. Acesso em: 21 jul. 2015.

SAMPAIO, M. R. A.; PEREIRA, P. C. X. Habitação em São Paulo. Estudos Avançados, São Paulo, v. 17, n. 48, p. 167-183, mai./ago. 2003. Disponível em: <http://www.scielo. br/scielo.php?script=sci_arttext\&pid=S0103-40142003000200014>. Acesso em: 8 jul. 2015.

SÃO PAULO. Secretaria Municipal de Desenvolvimento Urbano. Projeto Nova Luz, São Paulo, Brasil. Projeto Urbanístico Específico. Subproduto 5.1: PUE Consolidado. São Paulo: PMSP, jul. 2011. Disponível em: <http://www.prefeitura.sp.gov.br/cidade/secretarias/upload/desenvolvimento_urbano/arquivos/nova_luz/201108_PUE.pdf>. Acesso em: 23 julho 2015.

SHIMBO, L. Z. Habitação social, habitação de mercado: a confluência entre Estado, empresas construtoras e capital financeiro. 2010. Tese (Doutorado em Arquitetura e Urbanismo) - Instituto de Arquitetura e Urbanismo, Universidade de São Paulo, São Carlos, 2010.

SILVA, H. M. B. (Coord). Oportunidades e limites para a produção de habitação social no centro de São Paulo. São Paulo: Lincoln Institute of Land Policy, nov. 2007. Disponível em: $<$ http://fau.usp.br/depprojeto/labhab/biblioteca/textos/silva_oportlimites_prodhabsocial.pdf>. Acesso em: 8 ago. 2016.

TATAGIBA, L.; PATERNIANI, S. Z.; TRINDADE, T. A. Ocupar, reivindicar, participar: sobre o repertório de ação do movimento de moradia de São Paulo. Opinião Pública, Campinas, v. 18, n. 2, p. 399-426, nov. 2012. Disponível em: <http://www.scielo.br/ scielo.php?script=sci_arttext\&pid=S0104-62762012000200007>. Acesso em: 10 jul. 2015.

ZANCHETTA, D. Intelectuais e sem-teto criam ocupação sustentável. O Estado de São Paulo, São Paulo, 11 ago. 2013. Disponível em: <http://sao-paulo.estadao.com.br/ blogs/diego-zanchetta/intelectuais-e-sem-teto-criam-ocupacao-sustentavel/>. Acesso em: 6 ago. 2015. 